\title{
The Impact of the Depth and Type of Soil Granulation Above the Bearing Capacity of the Ring Footing
}

\author{
Saeid Azmoodeh*, Nasser Arafati \\ Department of Civil Engineering, Tafresh University, Tafresh, Iran \\ Email address: \\ Saeid.azmoodeh66@gmail.com (S. Azmoodeh), Nasser.arafati@gmail.com (N. Arafati)
}

\section{To cite this article:}

Saeid Azmoodeh, Nasser Arafati. The Impact of the Depth and Type of Soil Granulation Above the Bearing Capacity of the Ring Footing. American Journal of Civil Engineering. Special Issue: Research and Practices of Civil Engineering in Developing Countries. Vol. 3, No. 2-2, 2015, pp. 75-79. doi: 10.11648/j.ajce.s.2015030202.25

\begin{abstract}
Obtaining bearing capacity of the footing is among the factors influencing the footings design. In this paper, the study of the type and depth impact of the soil granulation above the bearing capacity of the ring footing through the assistance of FLAC software is conducted. The failure criterion intended for the soil is Mohr-Coulomb. The study of the bearing capacity of ring footing of ten thousand cubic meter of Mazut tank of Mashhad Cement Company on three types of soil, topsoil, clay and sand has been carried out. The results indicate that the loading capacity increases by granularity becoming coarser due to the increase of the contact area of the granulation and the increase of friction and the soil structure stability. Also the less the poorer soil depth (in terms of granularity) is, the more limited subsidence is, hence the bearing capacity increases.
\end{abstract}

Keywords: Ring Footing, Bearing Capacity, Tank, Type of the Soil, FLAC Software

\section{Introduction}

Obtaining bearing capacity of the footing is among the factors influencing the footings design. Nowadays, several numerical and laboratory studies have been carried out to determine the bearing capacity of shallow footings above the soil. In the recent years, numerical methods such as: finite difference method and finite elements method have been used widely to calculate the bearing capacity of different types of footings including strip, circular and rectangular, etc.[7]

Now using ring footing underneath the structures, which have axial symmetry such as: chimneys, water and oil storage tanks, towers and silos due to economic issues is rising. Therefore, the calculation technique of bearing capacity of these footings is required to design and build them [3]. Of course, so far researches have also been carried out on bearing capacity and settlement of the ring footings, which among them, the studies Egorov (1965) [6] and Ohri (1997) [4] can be noted, which have led to the new relationship suggestions in this regard. Mr. Hatef and Boushehrian (2002), considering " $n$ " which is equal to the ratio of internal to external radius of the ring footing and through studying the bearing capacity above the sandy soil in the laboratory condition concluded that in $\mathrm{n}=0.4$, the bearing capacity reaches its maximum amount [2].

By using FLAC software and with the assistance of coding,
Wang and Zhao (2007) studied $\mathrm{N}_{2}$ coefficient on bearing capacity of ring footing placed on cohesion-less soil. The results indicated that by increasing the ratio of " $n$ ", the coefficient of $\mathrm{N}$ will also increase [9].

\section{Definition of the Problem}

The soils considered in the research with the Mohr-Coulomb failure criteria include: clay, sand and topsoil, which have been used in various depths underneath the footing. The characteristics desired for different types of soils can be observed in table 1 . In the case of the existence of 2 layers of soil, 2, 5 and 10 meters thicknesses for the topsoil is considered.

Table 1. Mechanical characteristics of soil.

\begin{tabular}{llllll}
\hline $\begin{array}{l}\text { Type of } \\
\text { soil }\end{array}$ & $\begin{array}{l}\text { Cohesion } \\
\text { (Kpa) }\end{array}$ & $\begin{array}{l}\text { Angle } \\
\text { friction } \\
\text { (degree) }\end{array}$ & $\begin{array}{l}\text { Poisson's } \\
\text { ratio }\end{array}$ & $\begin{array}{l}\text { Modulus of } \\
\text { elasticity } \\
\text { (Kpa) }\end{array}$ & $\begin{array}{l}\text { Density } \\
\left(\mathbf{K N / m ^ { \wedge } 3}\right)\end{array}$ \\
\hline Sand & 0 & 3 & 0.28 & 10000 & 17 \\
Clay & 25 & 0 & 0.35 & 20000 & 16 \\
Topsoil & 1 & 3 & 0.3 & 8000 & 16 \\
\hline
\end{tabular}

The sample under study is ten thousand cubic meter tank of storing Mazut of Mashhad Cement Company, which the 
footing underneath this tank is of ring type with the external diameter of 34 and internal diameter of 30 meters, the thickness of the footing is also 1 meter.
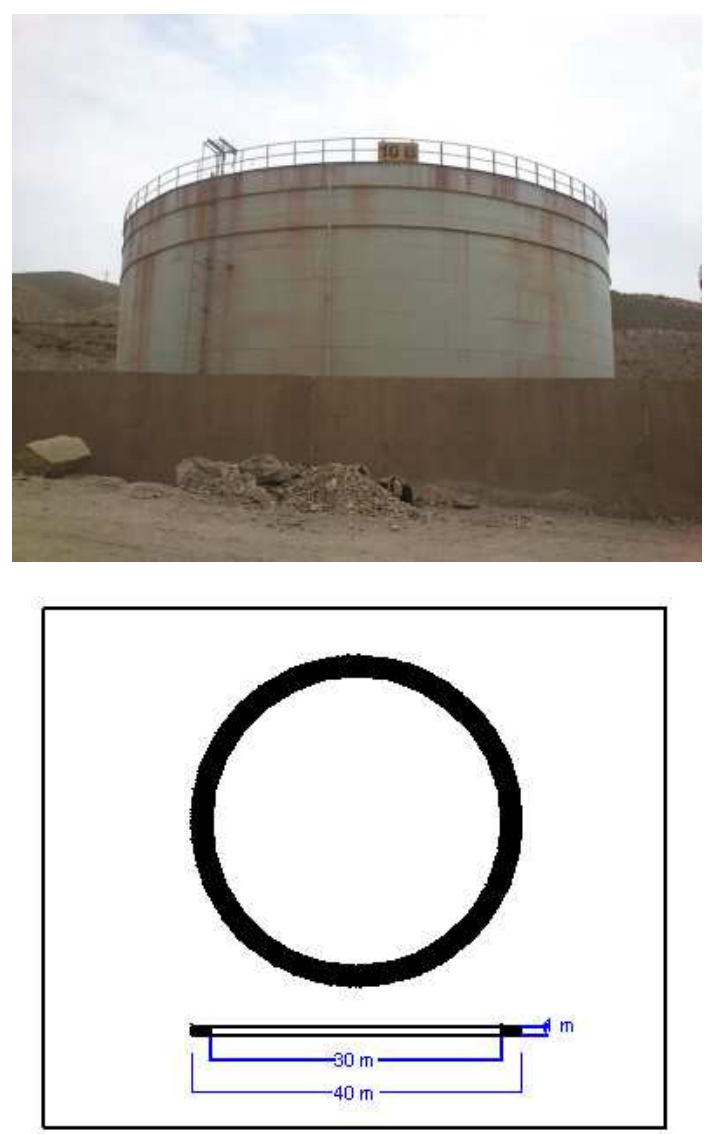

Figure 1. A view of the 10 thousand cubic meter Mazut tank of Mashhad Cement Company.

When soil is under steady pressure of (q), based on the "Terzaghi relations", the bearing capacity of the footing circular shallow footing can be obtained from the following equation:

$$
\mathrm{q}_{\mathrm{o}}=1.3 \mathrm{CN}_{\mathrm{c}}+\mathrm{qN}_{\mathrm{q}}+0.3 \times \mathrm{BN}_{\gamma}
$$

Where (C) equals cohesion, (q) represents the equivalent surcharge, ( $\mathrm{Y}$ ) soil density, (B) width or diameter of the footing and $\mathrm{N}_{\mathrm{c}}, \mathrm{N}_{\mathrm{q}}$ and $\mathrm{N}_{\mathrm{Y}}$ are bearing capacity coefficients related to the friction angle $(\varphi)$.

In the form of ring footing Ohri et al. relation (1997) is used. To obtain the bearing capacity of ring footing, Ohri has offered a coefficient called "Ring efficiency coefficient $\left(\mathrm{F}_{\mathrm{r}}\right)$ " which is equal to:

$$
\mathrm{F}_{\mathrm{r}}=\mathrm{q}_{\mathrm{n}} / \mathrm{q}_{\mathrm{o}}
$$

Where $\left(\mathrm{q}_{\mathrm{n}}\right)$ equals the final bearing capacity of ring footing and $\left(\mathrm{q}_{\mathrm{o}}\right)$ is bearing capacity of circular footing [4]. This coefficient, which is applicable for both types of footing with variable and fixed surfaces, can be obtained through having (n), which is the ratio of internal diameter to external diameter from figure 2, as it can be seen below.

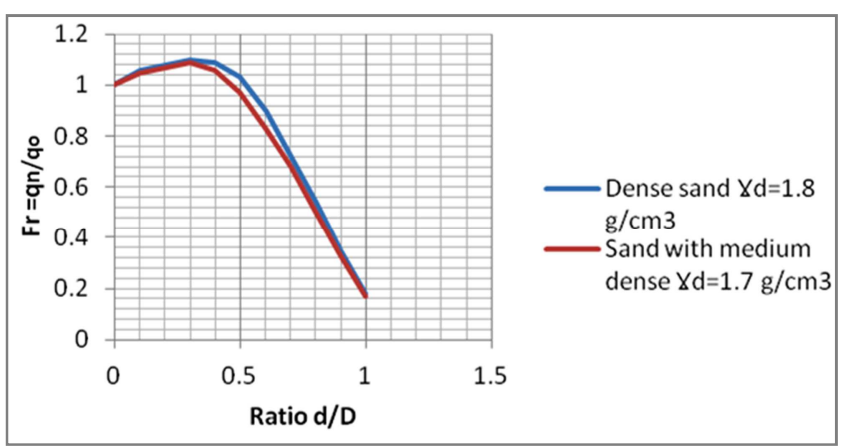

Figure 2. Ring efficiency coefficient curve (Fr) in comparison to $d / D$ (for variable surfaces but with identical external diameter) [4].

In this research, also the ratio of external diameter to internal diameter of the footing is shown with (n), where (n) equals 0.88 here. Most of the researches conducted on ring footing indicates that in the case where $n \geq 0.7$, the failure underneath the footing changes from the general mode to the positional mode [5], in this case instead of using $(\mathrm{C})$ and $(\varphi)$, we should apply $(\dot{C})$ and $(\varphi)$, which are corrected as follows [1]:

$$
\begin{gathered}
\dot{C}=2 / 3 \mathrm{C} \\
\varphi ́=\tan ^{-1}(2 / 3 \tan \varphi)
\end{gathered}
$$

It should be noted that in a state that the tank is full, the pressure resulting from the weight of Mazut inside the tank is exerted to all the surfaces of the circle, for this reason the bearing capacity is calculated first in the state of $n=0$ and then for $n=0.88$, which is equal to the real conditions of the model, until finally it is specified which soil will bear the exerted pressure from the tank. Of course this pressure with regard to the density of Mazut $\left(X=0.9 \mathrm{gr} / \mathrm{cm}^{3}\right)$ and the volume of 10 thousand cubic meter of the tank will be equal to $90000 \mathrm{KN}$.

\section{Numerical Simulation}

With regard to the external diameter and settlement distribution and tension underneath the footing, the bearing considered for this model is flexible. Modeling is done with the help of FLAC software, which is limited on the basis of Difference Method. Since the analysis under axial symmetry has the modeling ability of problems, which has an axis and the entire model studied from the rotation of a radial plate around symmetry axis can be modeled [10]. To analyze the ring footing desired, the axially symmetric condition, while the " $Y$ " axis is the entire symmetry axis, the entire model geometric shape (including soiled bed and bearing) is modeled through rotation of a radial plate around "Y" axis. With these conditions, only the right side of the model will be studied.

In order to estimate the bearing capacity of the footing, "Cross tangents" method on the graph of load-settlement is used. It is necessary to remind that in the state of the existence of 2 or 3 soil layers, an interface level between the soil layers

to create full cohesion and uniformity between two areas with different zoning should be taken into account, where this work is done in FLAC software through assigning vertical and sheer rigidity of adjacent zones (unit: tension over 
displacement) [10]. Figure 3 shows the zones intended for 3 soil layers through exerting the interface level conditions.

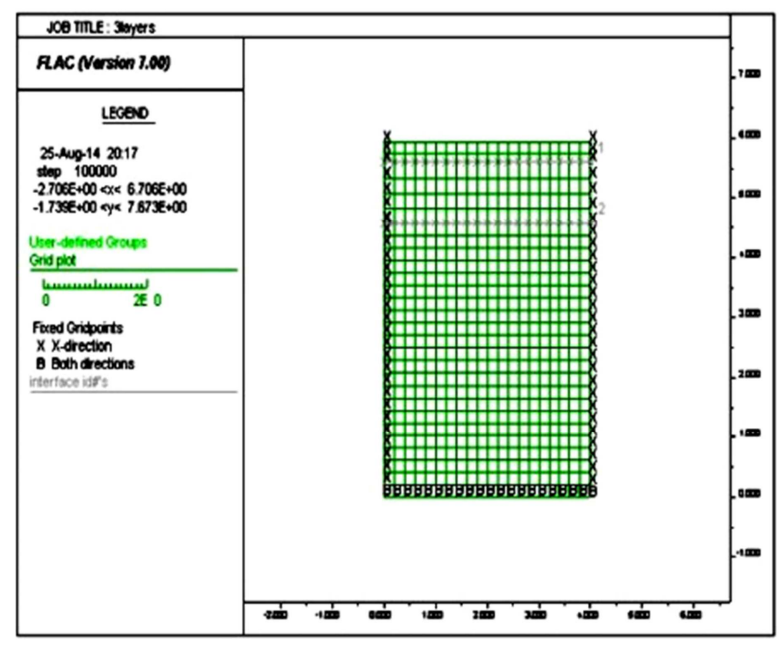

Figure 3. Intended zone for 3 soil layers.

\section{Analysis and Results}

Bearing capacity of ring footing on clay and sandy soil in modes $n=0,0.88$ was studied, where the load-settlement graph related to it can be seen in figure 4 . As it is seen, the bearing capacity of the footing above the sandy soil is more than the period, when the soil underneath the footing is from the clay type.

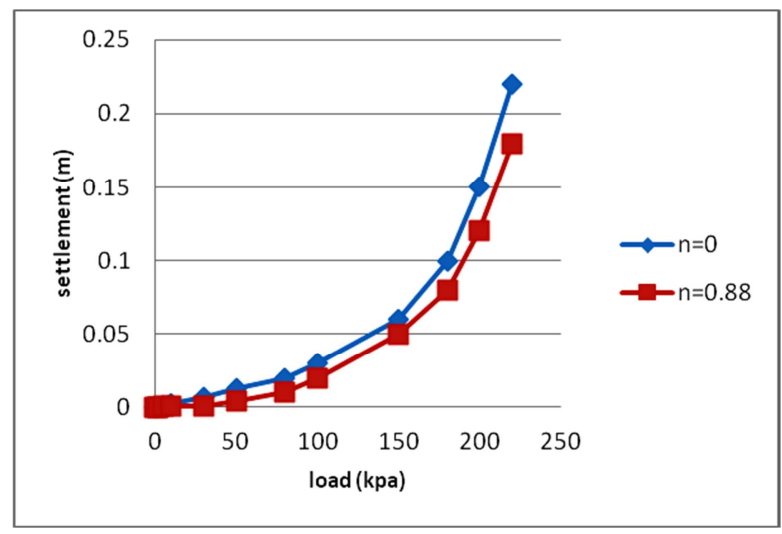

a) Sandy soil

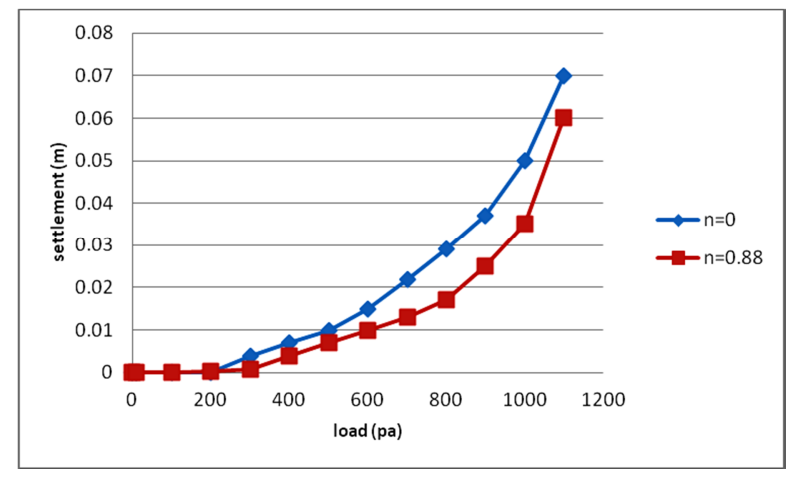

b) Clay soil

Figure 4. The figure of load-settlement for clay and sand.
In the mode of using 2 layers of soil, by considering different thickness for upper layers, load- settlement graph has been shown.

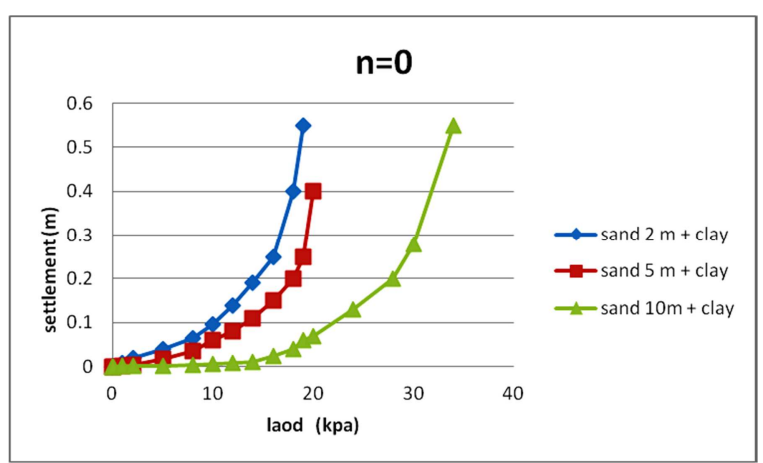

a) Sandy soil on clay, $n=0$

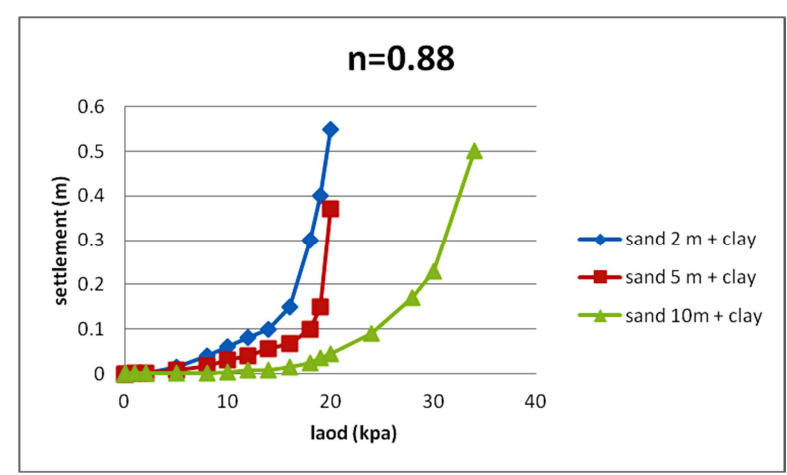

b) Sandy soil on clay, $n=0.88$

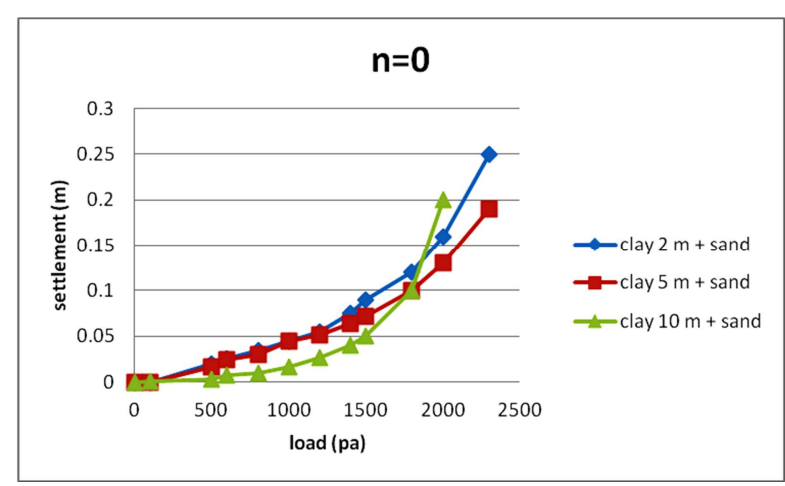

c) Clay above the sand soil, $\mathrm{n}=0$

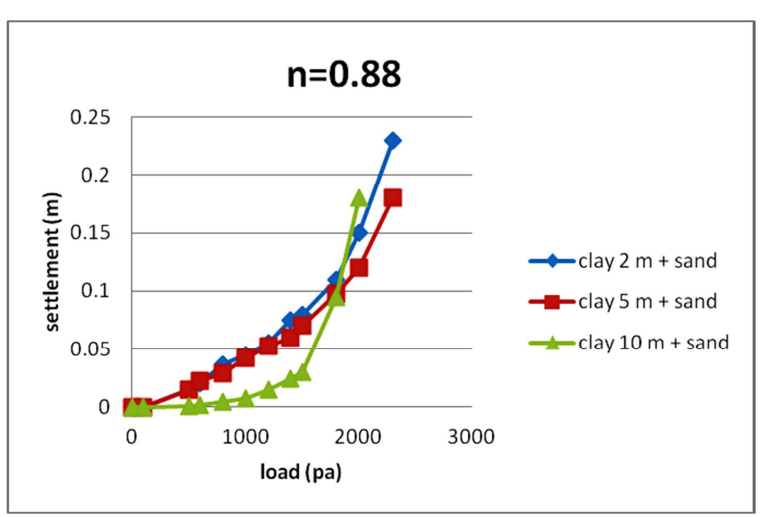

d) Clay above the sand soil, $\mathrm{n}=0.88$

Figure 5. Graph of load-settlement in the mode of existence of 2 soil layers. 
Figure 6. bearing capacity graph in terms of the depth shows the soil layer.

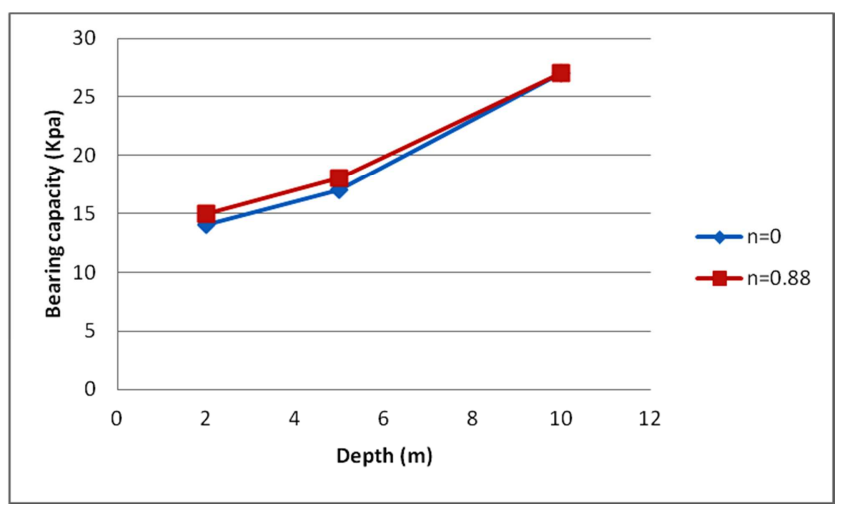

a) Upper layer of sandy soil

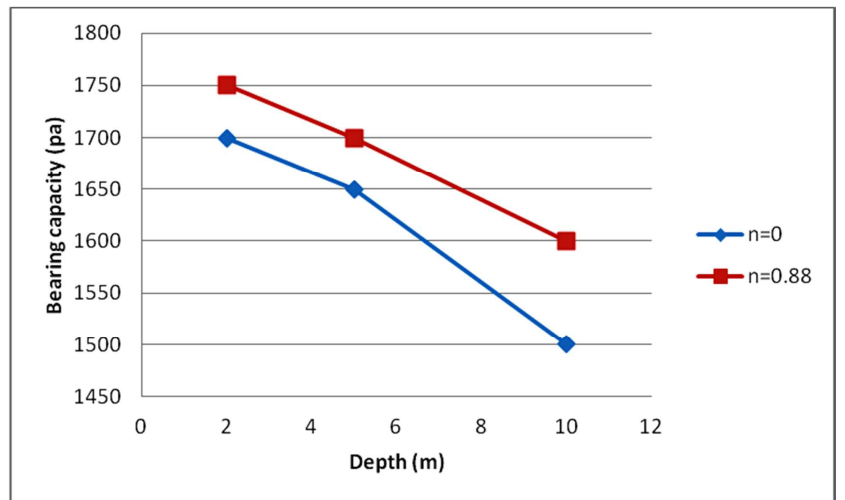

b) Upper layer of clay soil

Figure 6. Graph of bearing capacity in terms of depth.

From the graph, the bearing capacity in terms of depth can be seen, when the depth of the sand layer increases, the bearing capacity will also increase and this is when through the increase of the clay layer depth, the bearing capacity decreases. The range of subsidence and displacements of the soil in the mode of 2 layers of soil can be seen in figure 7.

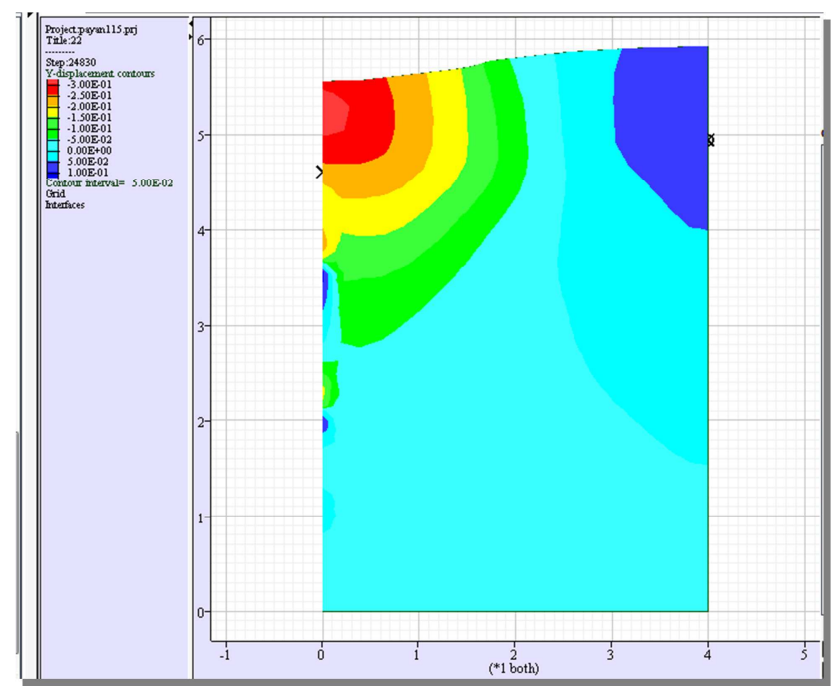

Figure 7. Settlement in the mode of existence of 2 soil layers.
The load- settlement graph obtained from the existence of 3 soil layers underneath the ring footing, in a mode that the Topsoil depth is 2 meters and it is in the upper layer has been given in figure 8 .

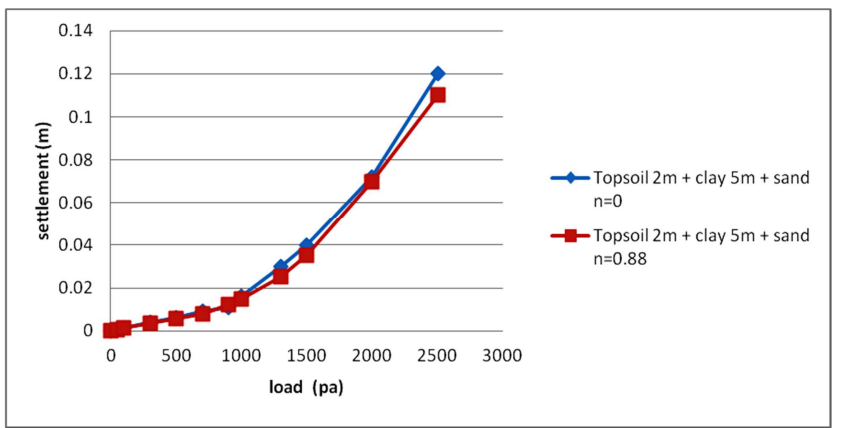

a) Topsoil on fine granulated soil

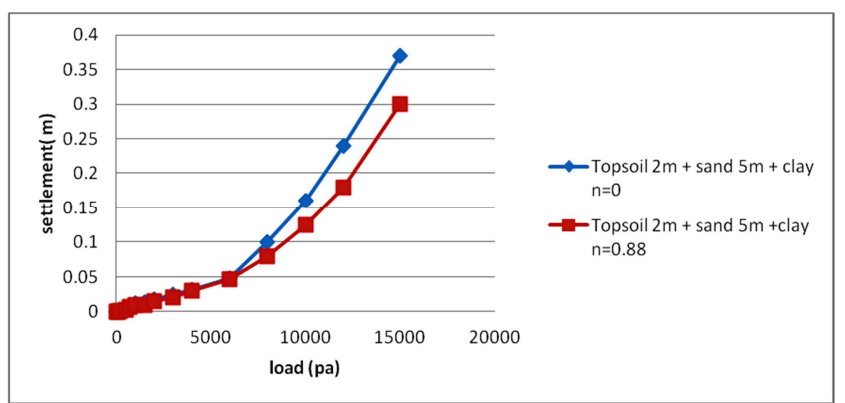

b) Topsoil on coarse granulated soil

Figure 8. Subside in the mode of the existence of the 3 layer soil.

The failure form of the soil taken place can also be seen in the following forms. As it can be seen in figure 9, the existence of coarse granulated soil underneath the Topsoil causes settlement being limited and ultimately, causes the increase of the bearing capacity. Also settlement in the Topsoil will afect the the clay very rapidly, when there is clay underneath it and this is when settlement above the coarse granulated sandy soil is very little.

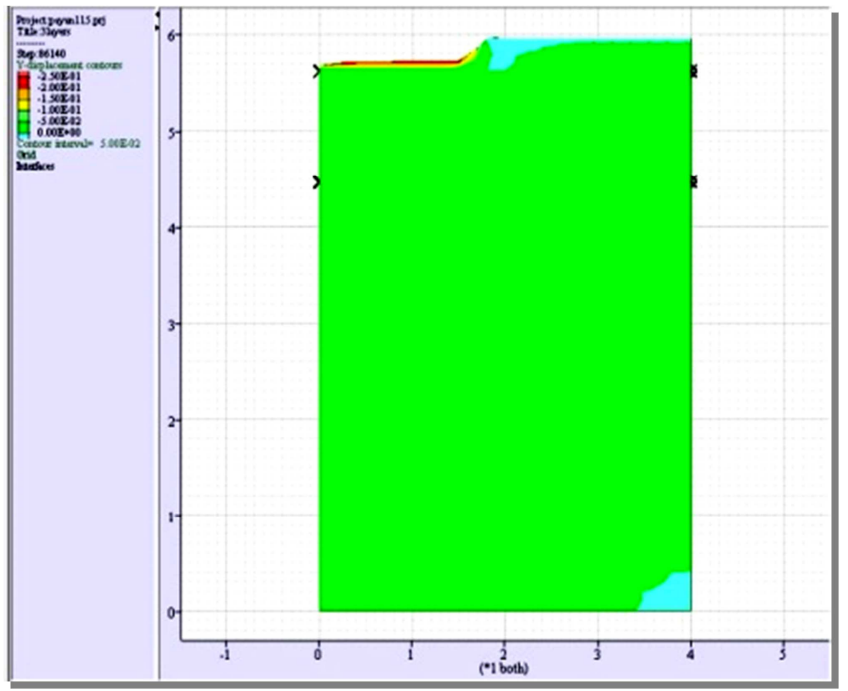

a) Topsoil on clay soil 


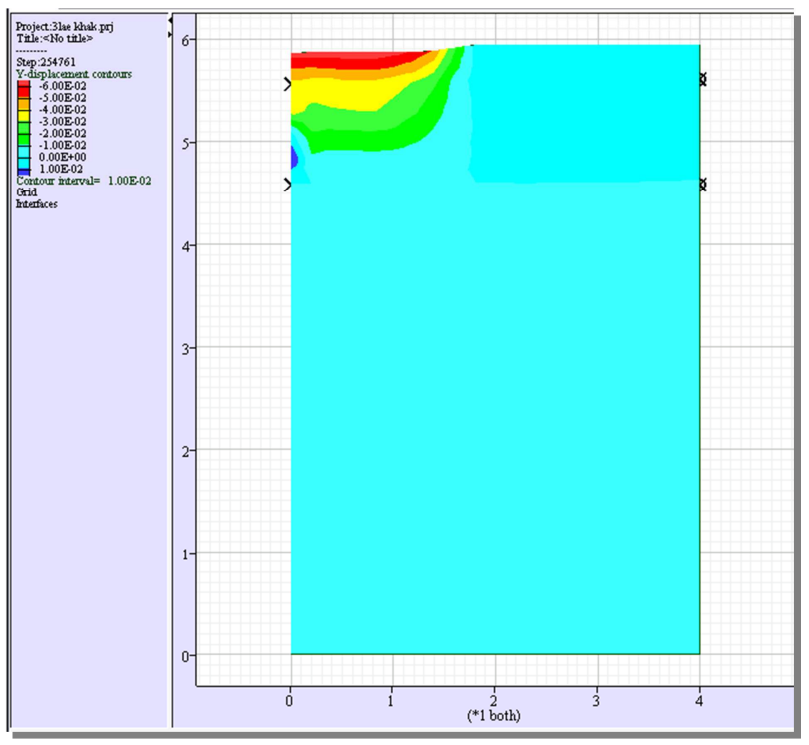

b) Topsoil on sandy soil

Figure 9. Soil failure in the mode of exerting load.

\section{Discussion and Conclusion}

Numerical simulation to estimated bearing capacity of ring footing on 1, $2 \& 3$ soil layers in different depths exists. topsoil clay and sandy soil with "Elasto-plastic" behavior and based on the Mohr-Coulomb "Yield criteria" was the granules with each other and as a result of the increase of the friction and soil structure stability. About the 2 layers of soil, the bearing capacity of the footing in two modes $n=0$ and $n=0.88$ above the sandy soil is much more than the time, when the soil underneath the footing is of the clay type. Also with the increase of the clay layer depth, the subsidence will be more and the bearing capacity will decrease. symmetric conditions was calculated. The calculations show that the bearing capacity has increased by coarsening of garrulity bearing capacity with the help of FLAC software in the axially. modeled and the reason can be the increase of the contact surface of In the mode of 3 layers of soil the results indicate that with the decrease of the depth of the weaker layer (in terms of granulation) the failures will be restricted and the tolerance of the soil under the pressure will be more.

\section{References}

[1] Tahoni SH.(2011).His translation of the book Principles of Geotechnical Engineering Braja M. Das, pp.150-153.

[2] Boushehrian JH, Hataf N (2002). Expermental and numerical investigation of the bearing capacity of model circular and ring footing on reinforced sand. Geotext Geomemberanes 2003; 21: 241-56.

[3] Hataf, N, Razavi, MR, (2003) Behavior of ring footing on sand. Iranian Journal of science and Technology, Transaction B, vol. 27, pp.47-56.

[4] Ohri, M.L, Purhit, D.G.M, Dubey, M.L, (1997). Behavior of ring footing on dune sand overlaying dense sand. Pres In ternational conference of civil Engineers, Tehran, Iran. p.4-6.

[5] Fisher, K.(1957).Zur Berechnung der setzung von foundamenten in der form einer kreisformigen ringflache.Der Bauingenieur, vol. 32, No.5. German, pp.172-174.

[6] Egorov, K.E. (1965). Caclculation of bed for foundation with ring footing. Proceedings of the sixth International Conference on soil mechanical foundation of engineers. Vol.2, Montreal, pp. 41-43.

[7] KumarJ, Ghosh P. Bearing capacity factor Nc for ring footings using the method of characterishtics. Can Geotech J (2005); 40(3): 1474-84.

[8] Terzaghi K. Teoretical soil mechanics. New York: John Wiley and Sons; (1943). 1256-62.

[9] Zhao L. and Wang, J.H. (2007), Vertical bearing capacity for ring footing, Computers and Geotechnical 35 (2009) 292-304.

[10] Zamirian S. (2012), The book modeling and analysis of soil and rock structures in FLAC, Siavash mind. p.123-148. 